\title{
THE EFFECT OF SOIL ON SPATIAL VARIATION OF THE HERBACEOUS LAYER MODULATED BY OVERSTOREY IN AN EASTERN EUROPEAN POPLAR-WILLOW FOREST
}

\author{
OLEXANDER ZHUKOV ${ }^{1}$, OLGA KUNAH ${ }^{1}$, YULIA DUBININA², YULIA ZHUKOVA ${ }^{1}$, \\ DMYTRO GANZHA ${ }^{3}$
}

${ }^{1}$ Department of Zoology and Ecology, Oles Honchar Dnipro National University, pr. Gagarina, 72, 49010 Dnipro, Ukraine; e-mail: zhukov_dnipro@ukr.net

${ }^{2}$ Department of Ecology and Information Technologies, Melitopol Institute of Ecology and Social Technologies of the Open International University of Human Development “Ukraine", Interculturnaya St., 380, 72316 Melitopol, Ukraine; e-mail: dubinina4884@ya.ru

3“Dnieper-Orilskiy” Nature Reserve, 52030 Obukhovka, Dniprovsk district, Dnipropetrovsk region, Ukraine

\begin{abstract}
Zhukov O., Kunah O., Dubinina Y., Zhukova Y., Ganga D.: The effect of soil on spatial variation of the herbaceous layer modulated by overstorey in an Eastern European poplar-willow forest. Ekológia (Bratislava), Vol. 38, No. 3, p. 253-272, 2019.
\end{abstract}

The tree species composition can influence the dynamics of herbaceous species and enhance the spatial heterogeneity of the soil. But there is very little evidence on how both overstorey structure and soil properties affect the spatial variation of the herb layer. The aim of this study is to evaluate the factors of the soil and overstorey structure by which it is possible to explain the fine-scale variation of herbaceous layer communities in an Eastern European poplar-willow forest. The research was conducted in the "Dnipro-Orils'kiy" Nature Reserve (Ukraine). The research polygon $\left(48^{\circ} 30^{\prime} 51^{\prime \prime} \mathrm{N}, 34^{\circ} 49^{\prime \prime} 02^{\prime \prime} \mathrm{E}\right)$ was laid in an Eastern European poplar-willow forest in the floodplain of the River Protich, which is a left inflow of the River Dnipro. The site consists of 7 transects. Each transect was made up of 15 test points. The distance between rows in the site was $3 \mathrm{~m}$. At the site, we established a plot of $45 \times 21 \mathrm{~m}$, with 105 subplots of $3 \times 3 \mathrm{~m}$ organized in a regular grid. The adjacent subplots were in close proximity. Vascular plant species lists were recorded at each $3 \times 3 \mathrm{~m}$ subplot along with visual estimates of species cover using the nine-degree Braun-Blanquet scale. Within the plot, all woody stems $\geq 1 \mathrm{~cm}$ in diameter at breast height were measured and mapped. Dixon's segregation index was calculated for tree species to quantify their relative spatial mixing. Based on geobotanical descriptions, a phytoindicative assessment of environmental factors according to the Didukh scale was made. The redundancy analysis was used for the analysis of variance in the herbaceous layer species composition. The geographic coordinates of sampling locations were used to generate a set of orthogonal eigenvector-based spatial variables. Two measurements of the overstorey spatial structure were applied: the distances from the nearest tree of each species and the distance based on the evaluation of spatial density of point objects, which are separate trees. In both cases, the distance matrix of sampling locations was calculated, which provided the opportunity to generate eigenvector-based spatial variables. A kernel smoothed intensity function was used to compute the density of the trees' spatial distribution from the point patterns' data. Gaussian kernel functions with various bandwidths were used. The coordinates 


\begin{abstract}
of sampling locations in the space obtained after the conversion of the trees' spatial distribution densities were used to generate a set of orthogonal eigenvector-based spatial variables, each of them representing a pattern of particular scale within the extent of the bandwidth area structured according to distance and reciprocal placement of the trees. An overall test of random labelling reveals the total nonrandom distribution of the tree stems within the site. The unexplained variation consists of $43.8 \%$. The variation explained solely by soil variables is equal to $15.5 \%$, while the variation explained both by spatial and soil variables is $18.0 \%$. The measure of the overstorey spatial structure, which is based on the evaluation of its density enables us to obtain different estimations depending on the bandwidth. The bandwidth affects the explanatory capacity of the tree stand. A considerable part of the plant community variation explained by soil factors was spatially structured. The orthogonal eigenvector-based spatial variables (dbMEMs) approach can be extended to quantifying the effect of forest structures on the herbaceous layer community. The measure of the overstorey spatial structure, which is based on the evaluation of its density, was very useful in explaining herbaceous layer community variation.
\end{abstract}

Key words: overstorey structure, soil properties, phytoindication, poplar-willow forest, scalogram, spatial eigenvector mapping.

\title{
Introduction
}

The greatest plant biodiversity in forest ecosystems is concentrated in the ground vegetation layer (Gilliam, 2007). Extinction rates in herbaceous plants are more than three times those of hardwood tree species and approximately five times those of gymnosperms (Levin, Wilson, 1976). The herbaceous layer has the potential to determine the overstorey species composition due to the fact that some herbaceous species may be superior competitors for soil nutrients, compared with tree seedlings (Lyon, Sharpe, 2003; Gilliam, 2007). The herbaceous layer plays an important role in the functioning of forest ecosystems by supplying high quality litter to the forest floor (Elliott et al., 2015). The herbaceous layer serves as habitat and food for other organism groups (Whigham, 2004). Herbaceous species can respond quickly to changed environmental conditions (von Oheimb, Härdtle, 2009).

There are two distinct explanations of community structure: niche assembly and dispersal assembly (Dallas, Drake, 2014). In accordance with niche assembly, community composition is controlled predominantly by environmental forces (Weiher et al., 2011). The scale of observation effects on the relative importance of specific environmental factors (Siefert et al., 2012) and the use of space across different scales in the community analysis could be useful (Gazol, Ibanez, 2010). Abiotic processes are generally considered as environmental filters, which select those species that match the specific habitat requirements (Silvertown et al., 2006; Lososová et al., 2015). Environmental filtering is probably not very important at finer scales (Chudomelová et al., 2017). Dispersal is the probability that a given patch will be colonized (King, With, 2002). Dispersal assembly suggests that community composition is forced by the ability of species to reach new habitats, making spatial variables stronger determinants of community composition than environmental variables (Weiher et al., 2011). Dispersal effects are important only within the confines of environmental gradients (Gilbert, Lechowicz, 2004). The influence of the environmental factors was revealed as progressively 
decreasing from broader to finer spatial scales (Laliberte et al., 2009). As scale becomes finer, dispersal or biotic processes such as interspecies interactions increase their importance (Gazol, Ibanez, 2010). Spatial distances may be considered as a surrogate for dispersal through space over time (Karst et al., 2005). Community composition and species distribution would be spatially structured independent of environment if dispersal limitation was a major assembly process (Jones et al., 2006; Aiba et al., 2012). Neutral processes become weaker as a consequence of the greater heterogeneity of environmental conditions (Nettesheim et al., 2018). By scaling down, the number of individuals within a given grain or extent is reduced, and individual-based stochastic processes become more important (Chase, 2014). As the size of the sampling plot decreased, the relative importance of environmental factors declined predominantly due to the reduction of environmental variability at finer scales (Frelich et al., 2003; Legendre et al., 2009).

Tobler's "first law of geography" says that everything is related to everything else, but near things are more related than distant things (Tobler, 1970). This law is the foundation of spatial autocorrelation. Spatial autocorrelation is the similarity between two observations of a measured variable based upon their spatial location (Griffith, 1992; Legendre, 1993; Lennon, 2000). Spatial autocorrelation considerably manifests itself at fine-scale level (Chudomelová et al., 2017). Spatial autocorrelation causes the problem of pseudoreplication. Pseudoreplication was defined as "the use of inferential statistics to test for treatment effects with data from experiments where either treatments are not replicated (though samples may be) or replicates are not statistically independent" (Hurlbert, 1984). Spatial autocorrelation of a species community is generated by intrinsic and extrinsic processes (Fortin, Dale, 2005). Environmental variables are the extrinsic forces that control species distribution (Legendre, Legendre, 2012). Dispersal, historical events and biotic elements are the intrinsic forces (Teng et al., 2018).

Explained variation in species composition can be separated into four parts: pure environmental variation, pure space variation, the variation explained both by environment and space, and unexplained variation (Borcard et al., 1992). Depending on the relative importance of niche explanations or dispersal processes, a community is considered to be controlled either by environmental or spatial factors (Cottenie, 2005). Variation explained purely by spatial variables represents partly unmeasured environmental variables with spatial structure (Legendre et al., 2009). The variation partitioning method results has been shown as being dependent on the quality of predictors. Spatially structured but unmeasured environmental variables may affect community composition (Jones et al., 2008). The degree of dispersal limitation contributes to both the pure environmental and pure spatial variance partitions. The assumption that a pure spatial component represents the role of dispersal limitation holds only in cases where all the relevant environmental variables are considered (Chang et al., 2013). The ratio of variation attributed to environmental variation depends not only on the strength of extrinsic processes, but also on the specific spatial patterns of the environmental factors (Smith, Lundholm, 2010).

The tree species composition can influence the dynamics of herbaceous species (Bratton, 1976) by changing light availability (Breshears et al., 1997) and enhancing the spatial heterogeneity of the soil (Andivia et al., 2015). When the spatial pattern in species composition of the overstorey forest stratum is significantly correlated with that of the herb layer stratum, 
the strata are said to be linked (Mölder et al., 2008). Herb-layer species are sensitive ecological indicators (Standovár et al., 2006). The herb layer and overstorey respond to different gradients in young stands but respond to similar gradients in increasingly similar ways as the stand matures (Gilliam et al., 1995). However, there is very little evidence on how both overstorey structure and soil properties effect herb layer spatial variation.

The aim of this study is to evaluate by which soil and overstory structure factors it is possible to explain the fine-scale variation of herb layer communities in an Eastern European poplar-willow forest. The first hypothesis is that the overstorey is able to spatially structure the soil properties, which in turn affect the variation of forest herb layer communities. The second hypothesis is that tree spatial patterns form complex structures whose effect may be best modeled on the basis of density dependent rather than distance dependent measures.

\section{Material and methods}

\section{Study area}

The research was conducted in the "Dnipro-Orils'kiy" Nature Reserve (Ukraine) (Fig. 1). The research polygon $\left(48^{\circ} 30^{\prime} 51^{\prime \prime} \mathrm{N}, 34^{\circ} 49^{\prime \prime} 02^{\prime \prime} \mathrm{E}\right)$ was laid in an Eastern European poplar-willow forest in the floodplain of the River Protich, which is a left inflow of the River Dnipro. The territory has a temperate-continental climate with an annual mean maximum decade temperature of $25.7^{\circ} \mathrm{C}$, and a minimum of $-10.0^{\circ} \mathrm{C}$, and with a mean annual precipitation of approximately $565 \mathrm{~mm}$ (20 year average according to data of the Dnipro meteorological station).

The study site comprises 1.0 ha of deciduous woodland bordered by arena terrace above floodplain of the River Dnipro. Forests in the steppe zone of Ukraine have a very restricted distribution and usually have an island status. The soils are fertile sandy loam, the underlying geology comprises Quaternary Aeolian sandy sediments.

\section{Data collection}

The site consisted of 7 transects. Each transect was made up of 15 test points. The distance between rows in the site was $3 \mathrm{~m}$. At the site, we established a plot of $45 \times 21 \mathrm{~m}$, with 105 subplots of $3 \times 3 \mathrm{~m}$ organized in a regular grid. The adjacent subplots were in close proximity. Vascular plant species lists were recorded for each $3 \times 3 \mathrm{~m}$ subplot along with visual estimates of species cover using the nine-degree Braun-Blanquet scale (Westhoff, van der Maarel, 1978). The projective cover of plant species was recorded at ground level, the understorey (up to $2 \mathrm{~m}$ height) and canopy (above $2 \mathrm{~m}$ height). We were able to make species level identification for all quadrats. Seedlings and saplings of woody species were later excluded from the analyses. Within the plot, all woody stems $\geq 1 \mathrm{~cm}$ in diameter at breast height were measured and mapped. Dixon's segregation index was calculated for tree species to quantify their relative spatial mixing. The measure of segregation describes the tendency of one species to be associated with itself or with other species (Dixon, 2002).

In syntaxonomic aspect, the vegetation can be identified as follows:

Class Salicetea purpureae Moor 1958,

Ordo Salicetalia purpureae Moor 1958,

Union Salicion albae R.Tx. 1955,

Ass. Populetum albae Br.-Bl.1931.

Based on geobotanical descriptions, phytoindicative assessment of environmental factors according to Didukh (2011) was made. Didukh phytoindication scales (2011) include edaphic and climatic scales. The edaphic phytoindication scales include soil water regime $(\mathrm{Hd})$, variability of damping $(\mathrm{fH})$, soil aeration $(\mathrm{Ae})$, soil acidity $(\mathrm{Rc})$, total salt regime $(\mathrm{Sl})$, carbonate content in the soil $(\mathrm{Ca})$ and nitrogen content in the soil $(\mathrm{Nt})$. The climatic scales include the parameters of thermal climate (thermoregime, Tm), humidity $(\mathrm{Om})$, cryo-climate $(\mathrm{Cr})$ and the continentality of climate (Kn). In addition to these, the lighting scale (Lc) is highlighted, which is characterized as a microclimate scale. Thermal properties of soils are indicated by the scale of thermal regime, and hydrothermal is the scale of ombro mode. Phytoindicational evaluation of environmental factors was performed by the ideal indicator method of Buzuk (2017). 
Measurement of soil mechanical impedance was carried out in the field using a hand penetrometer Eijkelkamp, to a depth of $100 \mathrm{~cm}$ with an interval of $5 \mathrm{~cm}$. The average error of the measurement results of the device is $\pm 8 \%$. The measurements were made by a cone with a cross-sectional dimension of $2 \mathrm{~cm}^{2}$. Within each measurement point, the mechanical impedance of the soil was made in a single repeatability. To measure the electrical conductivity of the soil in situ, a sensor HI 76305 was used (Hanna Instruments, Woonsocket, R. I.). This sensor works in conjunction with the portable device HI 993310. The tester estimates the total electrical conductivity of the soil, that is, combined conductivity of soil air, water and particles. The results of measurements of the device are presented in units of saturation of the soil solution with salts as g/l. Comparison of measurement results of $\mathrm{HI} 76305$ with laboratory data allowed us to estimate the conversion factor of units as $1 \mathrm{dS} / \mathrm{m}=155 \mathrm{mg} / \mathrm{l}$ (Pennisi, van Iersel, 2002). The soil bulk density was estimated by Kachinskiy, soil moisture by weight method (Vadunina, Korchagina, 1986). The aggregate structure was evaluated by the dry sieving method according to Savinov (Vadunina, Korchagina, 1986). The percentage content of such fractions is established: $<0.25,0.25-0.5,0.5-1,1-2$, $2-3,3-5,5-7,7-10,>10 \mathrm{~mm}$. Litter layer thickness was measured by a ruler at 5 sampling points per sample subplot.

\section{Data analyses}

Soil aggregate structure is presented by the vectors of $n$ ( $n=9$ in our case) strictly positive real components $\left(x_{1}, x_{2}, \ldots, x_{n}\right)$, such that $x_{1}+x_{2}+\cdots+x_{n}=\kappa>0$, where $\kappa$ is 100 (percentages) or 1 (proportions). Therefore, soil aggregate fractions are related to each other and any change in one fraction must affect the other fractions (Aitchison, 1986). Soil compositions were handled statistically using $\log$ ratio transformations (Parent et al., 2012). Isometric log ratios are orthogonal projections of compositional data (Egozcue et al., 2003). Due to there being D-1 degrees of freedom in compositional vectors (Aitchison, Greenacre, 2002), for the 9 soil aggregate fractions, there are 8 isometric log ratio variables (ILR-variables). The basis for isometric log-ratio transformation of the compositions data was computed by such methods as basic, balanced, optimal and principal balance methods (PBhclust, PBmaxvar, and PBangprox) (Egozcue et al., 2003). In order to select the optimal basis of the transformation, the matrix of distances of the sampling points in the space of the ILR-variables was compared with the matrix of distances of the sample points in the space of soil physical properties (electrical conductivity, soil mechanical impedance, bulk density and moisture), and with the distances matrix in the space of phytoindication scales and the matrix in the space of distances from tree stems. The evaluation was performed by
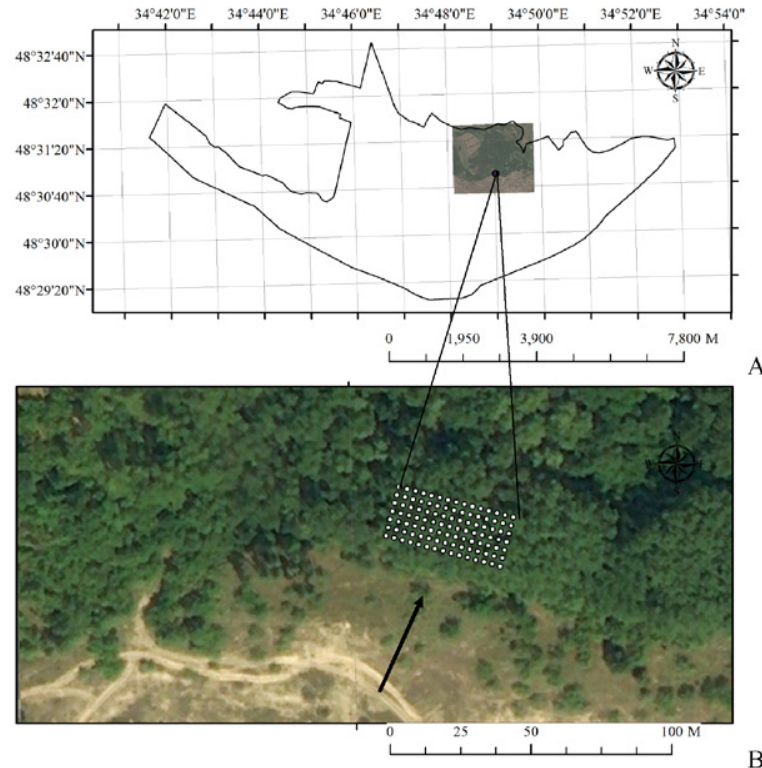

B

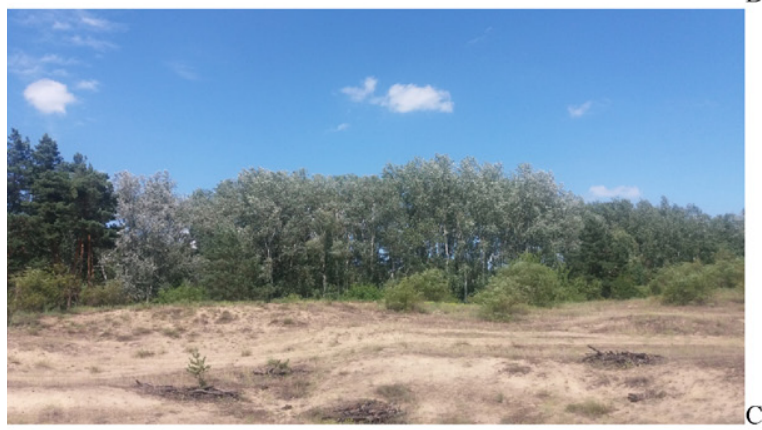

Fig. 1. Placing of experimental polygon and the sampling points. A - the map of the "Dnipro-Orils'kiy" Nature Reserve; B - the satellite image of the territory around the research polygon; $\mathrm{C}$ - photo of the research polygon (arrow shows the direction of the photographic shoot). 
using the Mantel test (ordinal and partial with matrix of the geographical distances as a conditional matrix). We assumed that transformation should lead to a solution that correlates best with the other properties of the environment and such correlation should not be spatially conditioned.

Redundancy analysis (RDA) was used for the analysis of variance in herb layer species composition (Rao, 1964). Before the analyses, percentage cover of species was Hellinger transformed to avoid problematic Euclidean distances used in the RDA (Legendre, Gallagher, 2001). Soil mechanical impedance, soil electrical conductivity, litter layer thickness, soil temperature, moisture and soil bulk density were log transformed. The significance of RDA global model including all soil variables was first tested. A soil model based on the forward selection of soil variables was built with double stopping rule (alpha significance level and the $R_{\text {adj }}^{2}$ calculated using all explanatory variables) (Blanchet et al., 2008; Chudomelova et al., 2017). Variables were retained only with a significant relationship to community composition ( $p<0.05,9999$ permutations). The models' marginal effect was computed, in which each selected soil variable was used separately as a predictor of community composition and the significance of all the models was tested and $R_{a d j}^{2}$ was extracted.

The geographic coordinates of sampling locations were used to generate a set of orthogonal eigenvector-based spatial variables (dbMEMs), each of them representing a pattern of particular scale within the extent of the sampling area (Borcard, Legendre, 2002). The forward-selection procedure on partial RDAs with previously selected soil factors as covariables was applied to the subset of spatial variables. The significance of soil models with selected spatial variables as covariables was tested by the Monte Carlo permutation test (9999 permutations).

Two measures of the overstorey spatial structure were applied: distances from the nearest tree of each species and the distance based on the evaluation of spatial density of point objects, which are separate trees. In both cases, the distance matrix of sampling locations was calculated, which provided the opportunity to generate eigenvectorbased spatial variables (dbMEMs-tree and dbMEMs-density based respectively). A kernel smoothed intensity function was used to compute the density of the trees' spatial distribution from the point patterns data. Gaussian kernel functions with various bandwidths were used. The density of the trees' spatial distribution for each species was converted into the distance measure:

$$
\text { Dist }=1-\text { dens, }
$$

where dens - density of the trees' spatial distribution, Dist - measure of the distance. The coordinates of sampling locations in the space obtained after the conversion of the trees' spatial distribution densities were used to generate a set of orthogonal eigenvector-based spatial variables (dbMEMs-density), each of them representing a pattern of particular scale within the extent of the bandwidth area structured according to distance and reciprocal placement of the trees. The forward-selection procedure on partial RDAs with previously selected soil factors as covariables was applied to the subset of tree-structured spatial variables and the significance of environmental models with selected spatial variables as covariables was tested by the Monte Carlo permutation test (9999 permutations).

In the next phase of the study, the dbMEMs were forward-selected directly on community data to explore patterns in community variation by variance partitioning between environmental and spatial influence. The significance of pure spatial and environmental fractions was tested by Monte Carlo permutation tests with 999. The scalogram approach was applied to inspect in detail the spatial scaling of community variation (Legendre, Legendre, 2012). To do this, the two sets of RDA analyses were carried out with each of the dbMEM variables as a predictor. As a response variable, the first set of RDA analyses used raw (Hellinger-transformed) species data, while the second set used residuals of the environmental model in which forward-selected environmental variables acted as predictors (Chudomelova et al., 2017). From each RDA, we extracted $R_{\text {adj }}^{2}$ for individual dbMEMs and plotted them into juxtaposed barplots (Chang et al., 2013). Phytoindication estimation of the ecological factors (Didukh, 2011) was used to find an ecological interpretation of spatial structures in community composition not explained by environmental variables.

All the statistical analyses were conducted in R (v. 3.5.0., R Foundation for Statistical Computing, Vienna, AT), using the following packages: vegan (v. 2.5-2, https:/CRAN.R-project.org/package=vegan) for the multivariate analysis and for the computation of global and partial Moran's I. (Oksanen et al., 2018), adespatial (v. 0.3-2. https:// CRAN.R-project.org/package=adespatial) for the forward selection and for the generation of spatial filters (Dray et al., 2018), compositions (https://CRAN.R-project.org/package=compositions) for compositional data analysis (Boogaart et al., 2018), dixon for testing the spatial segregation and association based on contingency table analysis of the nearest neighbor count (De la Cruz, 2008), spatstat for density estimation of the tree stems' spatial distribution (Baddeley, Turner, 2005). 


\section{Results}

The forest overstorey includes Populus alba L. (41.5\% of total tree stems), Ulmus laevis Pall (40.7\%), and Crataegus fallacina Klokov (4.4\%). There are dead trees within the site (13.3 \%) (Fig. 2). The distance from the sampling locations to Populus alba stems is $2.0 \pm 0.094 \mathrm{~m}$ (maximum $-4.6 \mathrm{~m}$ ), to Ulmus laevis stems is $2.3 \pm 0.13 \mathrm{~m}$ (maximum $-7.6 \mathrm{~m}$ ), to Crataegus fallacina stems is $12.8 \pm 0.81 \mathrm{~m}$ (maximum $-30.6 \mathrm{~m}$ ), and to dead stems is $3.8 \pm 0.19 \mathrm{~m}$ (maximum $-9.1 \mathrm{~m})$.

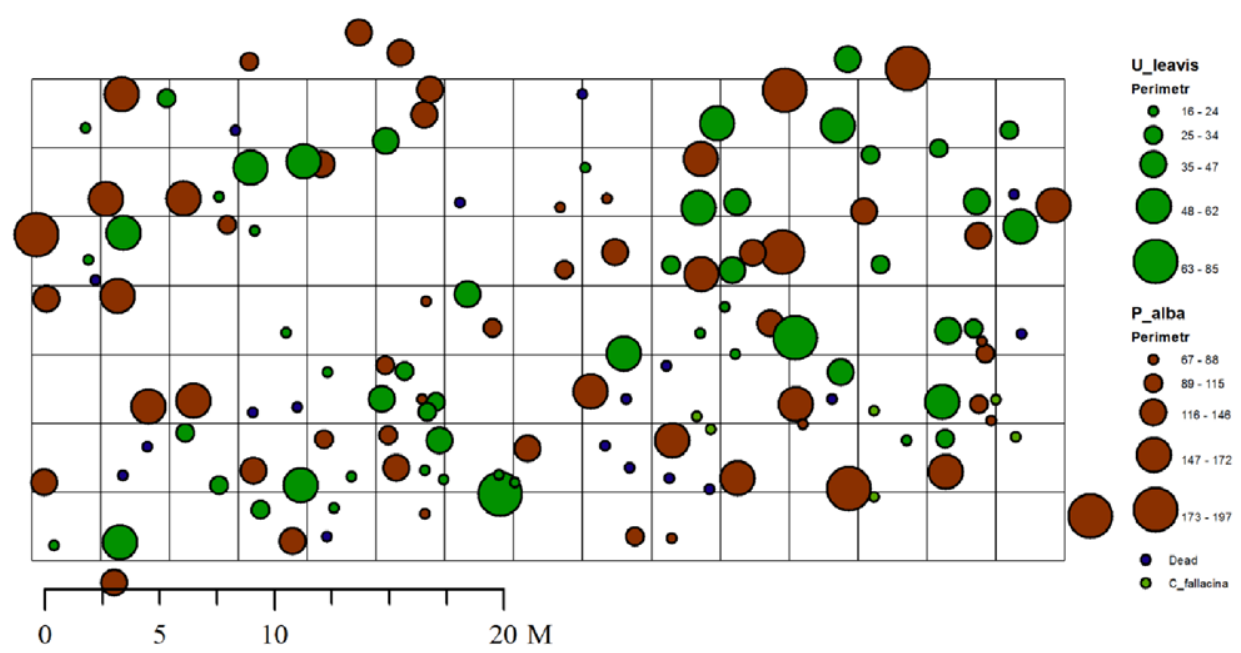

Fig. 2. Spatial locations of the three species individual within the site.

An overall test of random labelling reveals the total nonrandom distribution of the tree stems within the site (overall test of random labelling 21.1, $p$-value of the overall test from the asymptotic chi-square distribution with the appropriate degrees of freedom is 0.05$)$. The species-specific test of random labelling shows the nonrandom distribution of the C. fallacina $(11.1, p=0.01)$, while other species are distributed randomly. The nearest neighbor contingency table indicates the aggregated spatial distribution of the $C$. fallacina stems within site (Table 1). There is no direct spatial connection between C. fallacina and Ulmus laevis. The dead trees are distributed randomly. The Populus alba stems are distributed non-randomly with a tendency to regular pattern. The Ulmus laevis distribution is random.

The simple Mantel test revealed that the soil aggregate structure is closely related to the variability of other physical properties of the soil, phytoindication estimates of environmental factors and varies depending on the distance to the tree stems (Table 2). The partial Mantel test showed that there is a spatial component in the soil aggregate structure data that is independent from spatial structure both in physical properties and distance from the stems as the Mantel statistic controlling for the effect of space is not significantly different from zero 
$\mathrm{T}$ a b l e 1. The nearest neighbor contingency table and Dixon's spatial segregation test for tree species.

\begin{tabular}{|c|l|c|c|c|c|}
\hline \multicolumn{2}{|c|}{ Species } & C.fallacina & Dead & P. alba & U. leavis \\
\hline \multirow{4}{*}{ C. fallacina } & Obs.Count & 2 & 1 & 3 & 0 \\
\cline { 2 - 6 } & Exp. Count & 0.22 & 0.81 & 2.51 & 2.46 \\
\cline { 2 - 6 } & S & 1.11 & 0.11 & 0.14 & - \\
\cline { 2 - 6 } & $p$-value & 0.00 & 0.82 & 0.68 & 0.04 \\
\hline \multirow{5}{*}{ Dead } & Obs.Count & 0 & 5 & 5 & 8 \\
\cline { 2 - 6 } & Exp. Count & 0.81 & 2.28 & 7.52 & 7.39 \\
\cline { 2 - 6 } & S & - & 0.42 & -0.27 & 0.06 \\
\cline { 2 - 6 } & $p$-value & 0.35 & 0.12 & 0.23 & 0.77 \\
\hline \multirow{4}{*}{ P. alba } & Obs.Count & 4 & 8 & 15 & 29 \\
\cline { 2 - 6 } & Exp. Count & 2.51 & 7.52 & 22.99 & 22.99 \\
\cline { 2 - 6 } & S & 0.22 & 0.03 & -0.28 & 0.19 \\
\cline { 2 - 6 } & $p$-value & 0.31 & 0.85 & 0.05 & 0.11 \\
\hline \multirow{5}{*}{ U. leavis } & Obs.Count & -2.46 & 7.39 & 22.99 & 22.16 \\
\cline { 2 - 6 } & Exp. Count & - & 0.04 & 0.06 & -0.01 \\
\cline { 2 - 6 } & S & 0.09 & 0.80 & 0.59 & 0.97 \\
\cline { 2 - 6 } & $p$-value & & & \\
\hline
\end{tabular}

Notes: Obs.Count - observed nearest neighbor count; Exp. Count - expected nearest neighbor counts; $\mathrm{S}$ - segregation measure (values of $S$ larger than 0 indicate that species is segregated; the larger the value of $S$, the more extreme the segregation; values of $S$ less than 0 indicate that species is found as neighbor of itself less than expected under random labelling. Values of $S$ close to 0 are consistent with random labelling of the neighbors of species); $p$-value based on the asymptotic normal distribution of the $\mathrm{Z}$ statistic.

$\mathrm{T}$ a b 1 e. 2. Correlation (Mantel test) between distances matrix of the sample points in space of the soil aggregate fraction after log ratios transformation on the different basis and distance matrix in the space of the physical properties, phytoindication scales and distance from the stems.

\begin{tabular}{|l|c|c|c|c|c|c|c|c|c|c|c|c|}
\hline $\begin{array}{l}\text { Basis of the } \\
\text { transforma- } \\
\text { tion }\end{array}$ & \multicolumn{4}{|c|}{ Physical properties } & \multicolumn{3}{c|}{ Phytoindication scales } & \multicolumn{3}{c|}{ Distance from the stems } \\
\cline { 2 - 16 } & Simple & p-level & Partial $^{*}$ & p-level & Simple & p-level & Partial $^{*}$ & p-level & Simple & p-level & Partial $^{*}$ & p-level $^{-1}$ \\
\hline Basic & 0.20 & 0.01 & -0.02 & 0.64 & 0.27 & 0.01 & 0.20 & 0.01 & 0.20 & 0.01 & 0.04 & 0.17 \\
\hline Balanced & 0.22 & 0.01 & 0.05 & 0.17 & 0.19 & 0.01 & 0.12 & 0.01 & 0.18 & 0.01 & 0.05 & 0.15 \\
\hline Optimal & 0.22 & 0.01 & -0.01 & 0.57 & 0.30 & 0.01 & 0.24 & 0.01 & 0.21 & 0.01 & 0.04 & 0.14 \\
\hline Pbhclust & 0.19 & 0.01 & -0.02 & 0.65 & 0.27 & 0.01 & 0.21 & 0.01 & 0.14 & 0.03 & -0.02 & 0.62 \\
\hline PBmaxvar & 0.18 & 0.002 & -0.03 & 0.70 & 0.24 & 0.01 & 0.16 & 0.01 & 0.20 & 0.01 & 0.05 & 0.20 \\
\hline PBangprox & 0.25 & 0.01 & 0.04 & 0.21 & 0.25 & 0.01 & 0.17 & 0.01 & 0.13 & 0.01 & -0.04 & 0.76 \\
\hline
\end{tabular}

Notes: ${ }^{*}$ - a partial Mantel statistic is calculated between the distance matrix obtained after soil aggregate fraction composition on the different basis and distance matrix in the space of the physical properties, phytoindication scales and distance from the stems controlling for the effect of geographic distance matrix.

(Legendre, Fortin, 1989). But the spatial structure in the soil aggregate fraction data is partly determined by the spatial gradient in the phytoindication scales and partly by other factors not explicitly identified in the study as the Mantel statistic controlling for the effect of space 
T a b l e. 3. Spearman correlation between soil aggregate fraction and variables after log ratios transformation (presenting statistically significant correlation coefficients with $p<0.05$ ).

\begin{tabular}{|c|c|c|c|c|c|c|c|c|}
\hline \multirow{2}{*}{$\begin{array}{c}\text { Aggregate } \\
\text { fraction, mm }\end{array}$} & \multicolumn{9}{|c|}{ Isometric log ratios variables } \\
\cline { 2 - 10 } & ILR_1 & ILR_2 & ILR_3 & ILR_4 & ILR_5 & ILR_6 & ILR_7 & ILR_8 \\
\hline$>10$ & -0.78 & 0.87 & 0.84 & 0.78 & 0.76 & 0.71 & 0.70 & 0.62 \\
\hline $7-10$ & - & 0.65 & 0.65 & 0.75 & 0.77 & 0.72 & 0.62 & 0.48 \\
\hline $5-7$ & - & - & 0.40 & 0.40 & 0.34 & 0.45 & 0.29 & 0.26 \\
\hline $3-5$ & - & 0.46 & 0.28 & 0.65 & 0.62 & 0.45 & 0.38 & 0.35 \\
\hline $2-3$ & - & 0.19 & 0.21 & - & 0.21 & 0.28 & 0.31 & 0.19 \\
\hline $1-2$ & - & - & - & -0.21 & -0.40 & - & - & - \\
\hline $0.5-1$ & - & - & -0.32 & -0.33 & -0.32 & -0.55 & - & - \\
\hline $0.25-0.5$ & 0.19 & -0.52 & -0.61 & -0.54 & -0.56 & -0.70 & -0.88 & -0.65 \\
\hline$<0.25$ & - & -0.28 & -0.40 & -0.34 & -0.31 & -0.45 & -0.64 & -0.87 \\
\hline
\end{tabular}
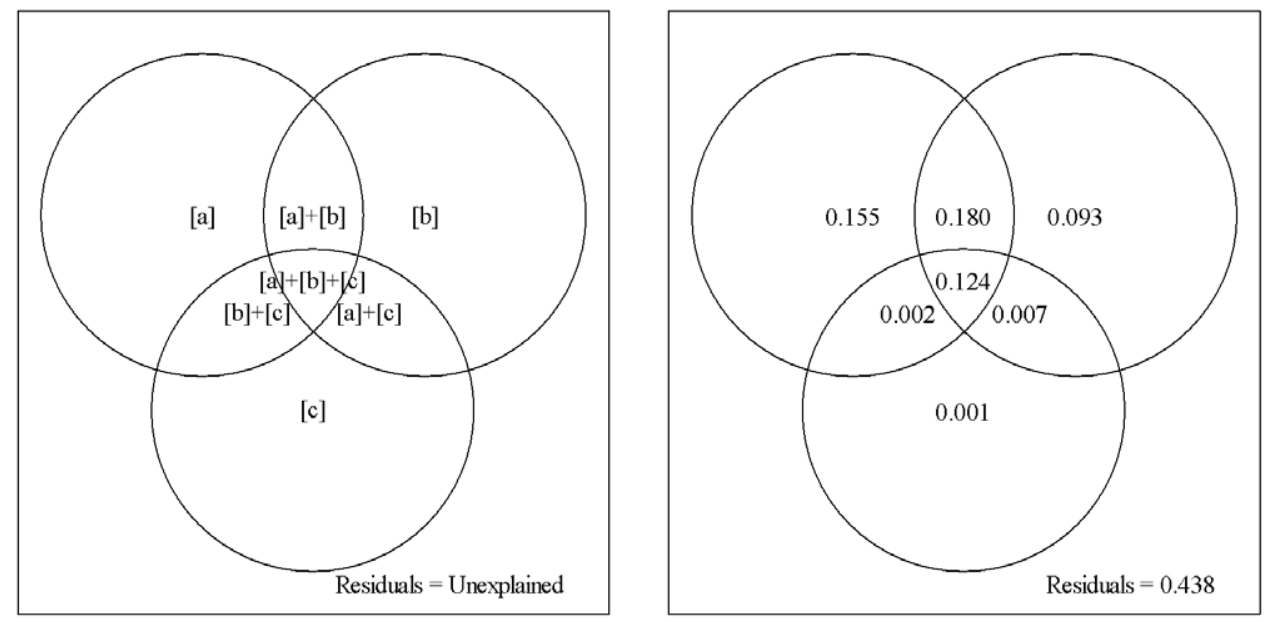

Fig. 3. Variance partitioning between spatial and soil explanatory variables.

Notes: [a] - variation explained solely by soil variables; [b] - variation captured by spatial (dbMEM) variables corresponds to pure space (residual spatial component); [c] - variation captured by distances from tree stems; $[a]+[b]$ - variation explained both by spatial and soil variables; $[a]+[\mathrm{c}]$ - variation explained both by spatial variables and distances from tree stems; $[\mathrm{b}]+[\mathrm{c}]$ - variation explained both by soil variables and distances from tree stems; $[a]+[b]+[c]-$ variation explained by spatial, soil variables and distances from tree stems. All the variance fractions shown are significant $(p<0.001)$.

is significantly different from zero. The maximal Mantel test was obtained after optimal basis of the log ratios' transformation of the soil aggregate fraction data. The Spearman correlation matrix between soil aggregate fraction and variables after log ratio transformation allows for better interpretation of the ILR-variables (Table 3). 

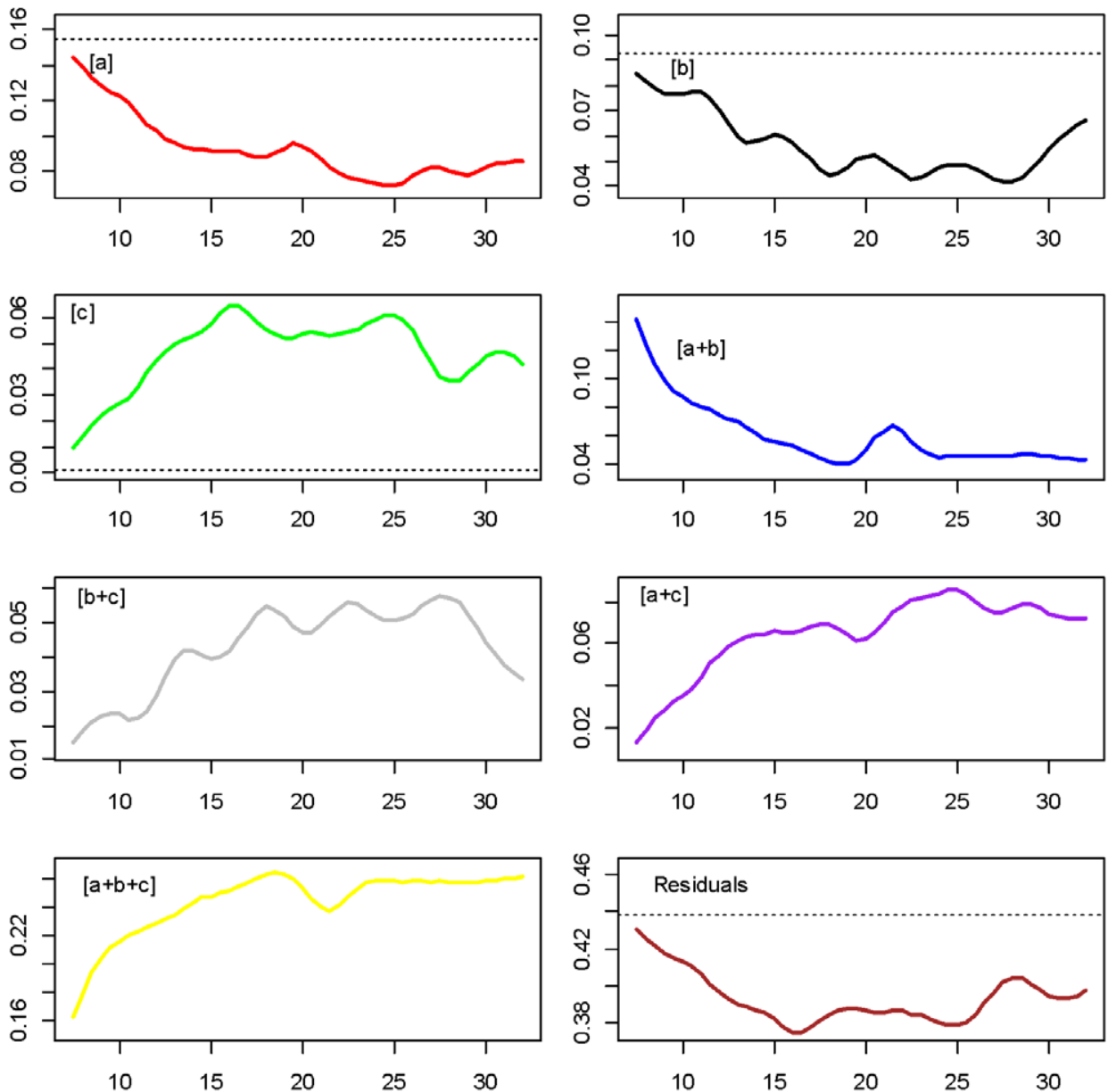

Fig. 4. Dependence of variation in herb-layer community composition from the bandwidth in evaluating the overstory density. Dotted line shows variation explained with tree-distance dbMEM variables. X-axis is a bandwidth, $\mathrm{y}$-axis is variation explained by explanatory tables.

Notes: [a] - variation explained solely by soil variables; [b] - variation captured by spatial (dbMEM) variables corresponds to pure space (residual spatial component); [c] - variation captured by trees density; $[\mathrm{a}]+[\mathrm{b}]$ - variation explained both by spatial and soil variables; $[\mathrm{a}]+[\mathrm{c}]$ - variation explained both by spatial variables and trees density; $[b]+[c]-$ variation explained both by soil variables and trees density; $[\mathrm{a}]+[\mathrm{b}]+[\mathrm{c}]-$ variation explained by spatial, soil variables and trees density.

The model of RDA including all soil variables was significant $\left(R_{a d j}^{2}=0.47, F=3.84, p<\right.$ $0.001)$. The forward selection procedure allowed us to select 19 soil variables, which explain $46.1 \%$ of the variability of the community $(F=5.94, \mathrm{p}<0.001)$. The list of the important soil variables includes soil mechanical impedance (at the depth $0-5,30-35,55-60,60-65,65-70$, 
C_fallacina

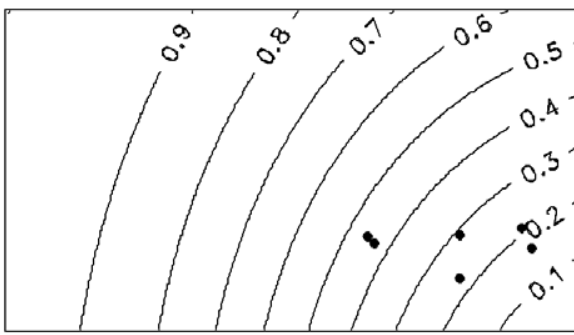

P_alba

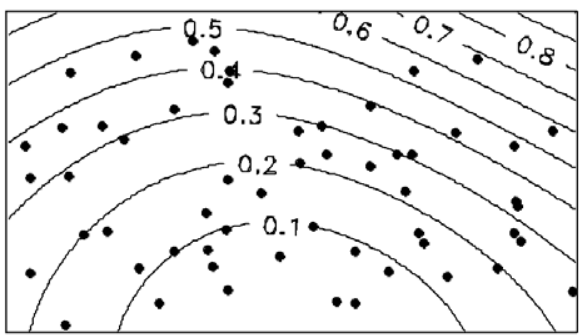

Dead

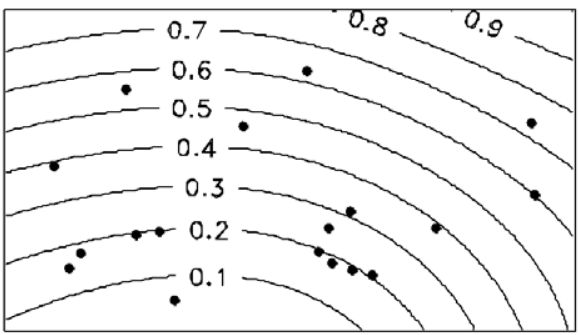

U_leavis

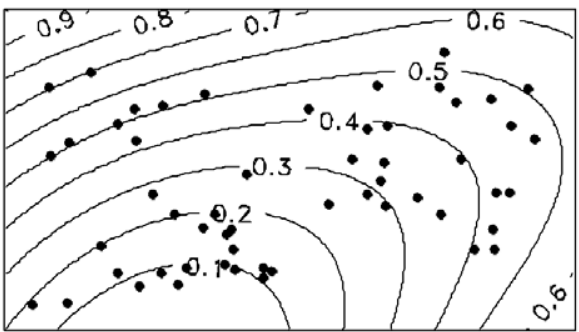

Fig. 5. Distance based on the density of the tree spatial distribution with bandwidth is equal to 17 . The points show tree location. Distance is normalized to diapason $0-1$.

75-80, 80-85, 85-90, and 90-95 cm), electrical conductivity, litter thickness, soil temperature, moisture, density and isometric log ratios variables $(2,3,4,6,7)$.

There are $48 \mathrm{dbMEMs}$-spatial variables with soil variables as covariates, which together explain $41.1 \%$ of the plant community variability. The forward selection procedure allowed us to select 20 variables, which explain $40.3 \%$ of the variability of the community $(F=11.04$, $\mathrm{p}<0.001)$.

The model of RDA including all dbMEMs-tree distance variables with soil variables as covariates was significant $\left(R_{\text {adj }}^{2}=0.15, F=1.49, p<0.001\right)$. The forward selection procedure allowed us to select 1 variable, which explains $0.7 \%$ of the variability of the community $(F=$ $2.29, \mathrm{p}<0.001)$.

The unexplained variation accounts for $43.8 \%$ (Fig. 3 ). The variation explained solely by soil variables is equal to $15.5 \%$, while the variation explained both by spatial and soil variables is $18.0 \%$.

The measure of the overstorey spatial structure, which is based on the evaluation of its density, enables us to obtain different estimations depending on the bandwidth. The bandwidth affects the explanatory capacity of the tree stand (Fig. 4). The lowest level of unexplained community variance obtained for bandwidth is equal to 17 . The assessment of tree stand density was obtained with this bandwidth (Fig. 5). The model of RDA including all 
$\mathrm{T}$ a b l e 4. Variation in plant community structure explained by the models with soil variables.

\begin{tabular}{|c|c|c|c|c|c|c|c|c|}
\hline Variable & $\begin{array}{c}\text { Marginal } \\
\text { effect } \\
R^{2}{ }_{a d j} \\
\end{array}$ & $p$-value & $\begin{array}{c}\text { Spatial partial } \\
\text { effect } \\
R_{a d j}^{2} \\
\end{array}$ & $p$-value & $\begin{array}{c}\text { Tree partial } \\
\text { effect } \\
\boldsymbol{R}_{a d j}^{2} \\
\end{array}$ & $p$-value & $\begin{array}{c}\text { Tree density } \\
\text { partial effect } \\
R_{a d j}^{2}\end{array}$ & $p$-value \\
\hline \multicolumn{9}{|c|}{ Soil mechanical impedance at depth, $\mathrm{MPa}$} \\
\hline $0-5 \mathrm{~cm}$ & 0.030 & 0.001 & 0.007 & 0.121 & 0.012 & 0.038 & -0.009 & 0.883 \\
\hline $30-35 \mathrm{~cm}$ & -0.001 & 0.487 & -0.002 & 0.616 & 0.010 & 0.045 & 0.039 & 0.024 \\
\hline $55-60 \mathrm{~cm}$ & -0.002 & 0.607 & 0.010 & 0.045 & -0.002 & 0.617 & 0.006 & 0.206 \\
\hline $60-65 \mathrm{~cm}$ & 0.018 & 0.014 & 0.003 & 0.239 & 0.027 & 0.004 & -0.009 & 0.873 \\
\hline $65-70 \mathrm{~cm}$ & 0.009 & 0.061 & 0.009 & 0.069 & 0.001 & 0.366 & 0.051 & 0.012 \\
\hline $75-80 \mathrm{~cm}$ & 0.048 & 0.001 & 0.006 & 0.117 & 0.036 & 0.001 & -0.010 & 0.974 \\
\hline $80-85 \mathrm{~cm}$ & 0.037 & 0.001 & 0.001 & 0.350 & 0.039 & 0.001 & 0.087 & 0.001 \\
\hline $85-90 \mathrm{~cm}$ & 0.028 & 0.001 & -0.006 & 0.920 & 0.020 & 0.005 & -0.003 & 0.406 \\
\hline $90-95 \mathrm{~cm}$ & 0.017 & 0.011 & -0.005 & 0.853 & 0.023 & 0.004 & -0.002 & 0.375 \\
\hline \multicolumn{9}{|c|}{ Other edaphic parameters } \\
\hline EC & 0.009 & 0.064 & 0.016 & 0.015 & 0.027 & 0.001 & 0.001 & 0.302 \\
\hline Litter & 0.057 & 0.001 & -0.003 & 0.657 & 0.041 & 0.001 & -0.005 & 0.483 \\
\hline Temp & 0.000 & 0.420 & 0.004 & 0.199 & 0.006 & 0.111 & 0.052 & 0.011 \\
\hline Moisture & 0.025 & 0.004 & 0.016 & 0.012 & 0.033 & 0.001 & -0.009 & 0.883 \\
\hline Density & 0.015 & 0.025 & 0.004 & 0.179 & 0.033 & 0.001 & 0.039 & 0.024 \\
\hline \multicolumn{9}{|c|}{ Isometric $\log$ ratios variables } \\
\hline ILR_2 & 0.013 & 0.023 & 0.008 & 0.067 & 0.027 & 0.001 & 0.006 & 0.206 \\
\hline ILR_3 & 0.005 & 0.130 & 0.003 & 0.241 & 0.024 & 0.003 & -0.009 & 0.873 \\
\hline ILR_4 & 0.018 & 0.009 & 0.004 & 0.193 & 0.030 & 0.001 & 0.051 & 0.012 \\
\hline ILR_6 & 0.010 & 0.053 & -0.002 & 0.596 & 0.031 & 0.001 & -0.010 & 0.974 \\
\hline ILR_7 & 0.000 & 0.388 & 0.002 & 0.303 & 0.025 & 0.004 & 0.087 & 0.001 \\
\hline
\end{tabular}

Notes: Marginal effect represents variation explained by a given variable without the effect of other variables in the model. $P$-value accounting for autocorrelation is a significance of soil model with selected eigenvector-based spatial variables (dbMEMs) as covariables; EC - Electrical conductivity, dSm/m; Litter - Litter depth, cm; Temp - soil temperature, ${ }^{\circ} \mathrm{C}$; Wetness - moisture of soil, \%; Density - soil density, $\mathrm{g} / \mathrm{cm}^{3}$.

dbMEMs-tree density distance variables was significant $\left(R_{\text {adj }}^{2}=0.46, F=1.48, p<0.001\right)$. The forward selection procedure allowed us to select 16 variables, which explain $11.8 \%$ of the variability of the community $(F=2.49, \mathrm{p}<0.001)$.

After accounting for spatial dependence in the model, considerable shifts in significance were detected for marginal effects of some variables (Table. 4). Variation explained by such variables as soil mechanical impedance at the depth $0-5,60-65,75-80,80-85,85-90$, and 90-95 cm, litter thickness, soil density, ILR 4, and ILR 6 is spatially structured, meaning that there is an decrease in variation explained by these soil factors after including spatial variables as covariates in the models. Variation explained by some soil variables is structured by the influence of trees. Tree density creates a much stronger effect on the plant community than variables derived from distance from the tree stems. This became evident after a decrease in the variation explained by the larger number of soil variables, if one takes into account 
the effect of the dbMEMs-tree density variables than if one takes into account the effect of the dbMEMs-tree distance variables.

The majority of both the spatially structured and treedistance structured variation in plant community composition was broad-scaled (captured by dbMEMs with lowest numbers) (Fig. 6). The soil models and pure spatial effect were able to account for mainly broad-to mesoscale variation.

We found that there is a range of values of bandwidth in which a higher level of explanation of the herbaceous layer community structure can be achieved than in the case of the use of distance to the nearest tree. The best explanation of the herbaceous layer community is due to the highest explanatory ability of the overstorey by means of density-dependent measure than tree-distance measure. Increasing the bandwidth up to the optimum value is accompanied by an increase in the number of density-dependent dbMEMs-variables (Fig. 7).

The significant relationship was found between soil induced community structure and phytoindication values of the soil acidity, carbonate content and aeration regime (Table 5). The significant rela-
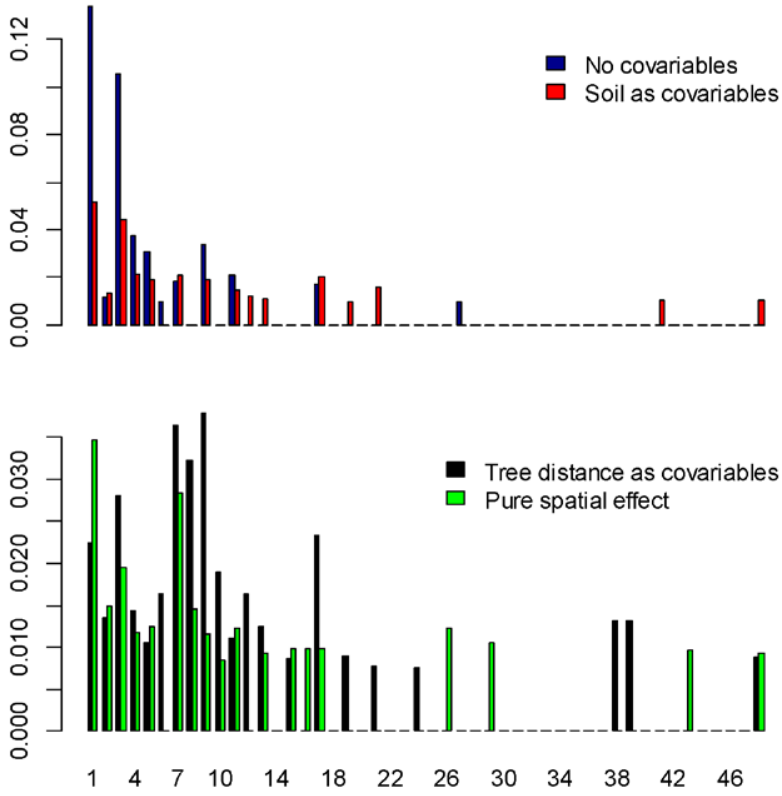

Fig. 6. Scalograms illustrating the scaling of spatially structured variation in community data (white bars) and residuals of the environmental models (black bars). The value of $R_{a d j}^{2}$ is the variation explained by individual dbMEM variables. The dbMEMs are ordered decreasingly according to the scale of spatial patterns they represent (dbMEM 1 represents the broadest scale, dbMEM 48 the finest scale).

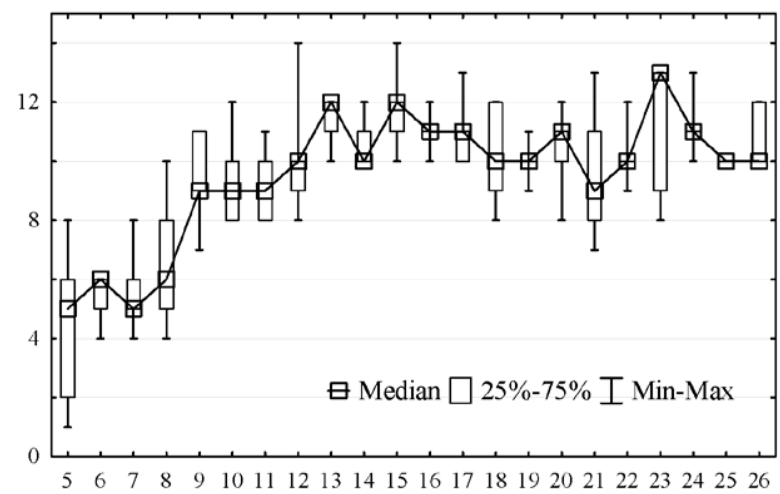

Fig. 7. Dependence of the number of the density-dependent dbMEMsvariables with a significant relationship to the community composition obtained after forward selection procedure from the bandwidth for tree density assessment. 
T a b l e 5. Significance of regression between subplot-based phytoindicator scale values and soil effects in the species data (first two RDA axes with soil predictors as explanatory variables), pure space (first two RDA axes with spatial predictors as explanatory variables and selected soil and tree-distance variables as covariables), tree distance effects (first RDA with tree distance predictors as explanatory variables and selected soil and spatial variables as covariables), and tree-distance variables as covariables), tree density effects (first RDA with tree density predictors as explanatory variables and selected soil and spatial variables as covariables).

\begin{tabular}{|c|c|c|c|c|c|c|c|c|}
\hline $\begin{array}{c}\text { Phytoindicator } \\
\text { scale }^{*}\end{array}$ & $\begin{array}{c}\text { Soil effect } \\
R_{a d j}^{2} \\
\end{array}$ & $p$-value & $\begin{array}{c}\text { Spatial partial } \\
\text { effect } \\
R_{a d j}^{2} \\
\end{array}$ & $p$-value & $\begin{array}{c}\text { Tree partial } \\
\text { effect } \\
R_{a d j}^{2}\end{array}$ & $p$-value & $\begin{array}{c}\text { Tree density } \\
\text { partial effect } \\
R_{a d j}^{2}\end{array}$ & $p$-value \\
\hline $\mathrm{Hd}$ & -0.01 & 0.55 & 0.00 & 0.34 & -0.01 & 0.88 & -0.01 & 0.90 \\
\hline $\mathrm{fH}$ & 0.01 & 0.17 & 0.00 & 0.40 & 0.04 & 0.02 & 0.04 & 0.02 \\
\hline $\mathrm{Rc}$ & 0.06 & 0.01 & 0.00 & 0.48 & 0.01 & 0.21 & 0.00 & 0.38 \\
\hline $\mathrm{Sl}$ & -0.01 & 0.58 & -0.01 & 0.96 & -0.01 & 0.87 & -0.01 & 0.79 \\
\hline $\mathrm{Ca}$ & 0.06 & 0.01 & 0.05 & 0.01 & 0.05 & 0.01 & 0.09 & 0.00 \\
\hline $\mathrm{Nt}$ & 0.00 & 0.25 & 0.01 & 0.21 & -0.01 & 0.97 & -0.01 & 0.80 \\
\hline $\mathrm{Ae}$ & 0.04 & 0.02 & 0.02 & 0.07 & 0.09 & 0.00 & 0.08 & 0.00 \\
\hline $\mathrm{Tm}$ & 0.01 & 0.14 & 0.00 & 0.27 & 0.00 & 0.41 & -0.01 & 0.52 \\
\hline $\mathrm{Om}$ & -0.01 & 0.87 & 0.01 & 0.22 & 0.00 & 0.37 & 0.00 & 0.32 \\
\hline $\mathrm{Kn}$ & -0.01 & 0.66 & 0.02 & 0.08 & 0.00 & 0.30 & 0.00 & 0.46 \\
\hline $\mathrm{Cr}$ & -0.01 & 0.51 & -0.01 & 0.93 & 0.00 & 0.48 & -0.01 & 0.66 \\
\hline $\mathrm{Lc}$ & 0.00 & 0.45 & 0.02 & 0.10 & 0.05 & 0.01 & 0.05 & 0.01 \\
\hline
\end{tabular}

Notes: ${ }^{\star} \mathrm{Hd}$ - soil water regime; $\mathrm{fH}$ - variability of damping; $\mathrm{Rc}$ - soil acidity; $\mathrm{Sl}$ - total salt regime; Ca - carbonate content in soil; $\mathrm{Nt}$ - nitrogen content in soil; Ae - soil aeration; Tm - thermal climate (thermoregime); Om - humidity; $\mathrm{Kn}$ - continentality of climate; $\mathrm{Cr}$ - cryo-climate; Lc - light.

tionship was found between the pure spatial component of the community variation and carbonate content. Tree distance and density effects are able to explain variability of damping, carbonate content, aeration and light regime.

\section{Discussion}

The small-scale variation of herb-layer community structure is influenced by the soil properties, structural features of the overstorey and neutral processes. The spatial factors may be considered as the markers of the neutral processes (Cottenie, 2005). The difficulty is that the variability of soil properties and effects of the overstorey also have a spatial component of its variation. There are reciprocal relationships between various components in the soil properties (Paluch, Gruba, 2012). Sunlight penetration through the canopy is directly related to the spatial pattern of the herbaceous layer (Blank, Carmel, 2012). The variability of the light caused by the stand density is often seen as the leading environmental regime, which determines the interactions between organisms and their physical environments (Stohlgren et al., 2000). This explains the widespread use of measuring light conditions under the canopy for assessment of the influence of the overstorey on the herbaceous layer (Chudomelova et al., 2017). It should be noted that the nature of influence of trees on herbaceous plants is much more complicated and involves the impact of trees on the habitat by modulating the avail- 
ability of resources to the other species (Jones et al., 1994). Trees are capable of modifying the properties of the soil in their vicinity (Binkley, Giardina, 1998). The pattern of soil properties under single forest trees is generally developed with radial symmetry to the tree, varying with distance from the tree trunk (Zinke, 1962). Tree species have a significant impact on humus characteristics, which significantly explain the distribution of forest understorey species (Oijen et al., 2005). The nearest distance to the tree species can be considered as a very apparent measure of influence on the herbaceous plants. The arrangement of different tree species can significantly complicate the structure of ecological space. The distance of the nearest tree is an easy and obvious measure of the impact of the overstorey, both on the herbaceous layer and soil. But it does not take into account the role of the relative positions of the trees of the same species. Tree density is sensitive to the number of trees of the same species per square unit. Evaluation of density can be measured with different bandwidths, which provides another opportunity for the modeling of scale-dependent effects.

We proposed that the dbMEMs-approach can be a useful tool for modeling the spatial effects of the overstorey. The coordinates of sampling locations used to generate a set of orthogonal eigenvector-based spatial variables (dbMEMs) may be calculated in the space of the distances to the nearest tree species or in the space opposite to tree densities. The value inverse to density can be considered as the distance from or between clusters of trees of the same species. This distance can also be used to calculate the dbMEMs variables. It must be noted that the dbMEMs approach is usually applied for modeling the geographical patterns within the extent of the sampling area (Borcard, Legendre, 2002) or time patterns from the beginning to the end of the sampling period (Legendre, Gauthier, 2014). The trees constitute a specifically structured space, in which a gradient of the environmental properties is formed in relation to the distance from the tree trunk. In this case, the extent is defined by the distance from the tree trunk to the sampling location farthest from the trunk of the tree. In the process of modeling, the extent may be varied, but the reference point is a single tree (in the case of estimation of distances) or the point with the highest density of the stand (in the case of density estimation). Spatial patterns in the specified extent can be modeled using the dbMEMs-variables.

If variables derived from tree distances are considered as the reference for comparison, it can be concluded that the change of the bandwidth for computing a kernel smoothed intensity function from a trees' point pattern can significantly increase the explanatory ability in general of the model based on the dbMEMs-tree density dependent variables. Using dbMEMs-tree density dependent variables calculated with bandwidth is 17 , which gives the possibility to reduce the unexplained component of the community variation from 43.8 to $37.5 \%$. The increase of the explanatory ability of the model is mainly due to the dbMEMs-tree density dependent variables. A considerable part of the variation explained by soil variables is tree structured, meaning that an increase in variation explained by dbMEMs-tree density dependent variables decreases the variation explained purely by spatial variables. It is clear that the overstorey is important for spatial variability of the soil properties. This conclusion is also confirmed by the fact that the bandwidth increase of up to an optimal level leads to higher importance of the variation explained by spatial variables and shared with tree density and both by soil variables and shares with tree density. 
The spatial heterogeneity of soil is mainly driven by the distribution of tree patches (Andivia et al., 2015). Our results revealed that the pure spatial component and the spatially structured soil properties are the most important factors that affect the herbaceous community. In turn, overstorey structure is more effective than pure effect of the soil properties. Soil variables are most important in explaining both broad-scaled and fine-scaled compositional patterns. In other studies, it was shown that environmental variables mostly explain broad-scaled compositional patterns (Laliberte et al., 2009; Legendre et al., 2009; Gazol, Ibanez, 2010; Chang et al., 2013; Chudomelova et al., 2017). We can explain this result by the ability of soil physical properties to form fine-scale patterns of an endogenous nature. Also, fine-scale morphological soil structure may be formed under the influence of trees. Morphological structure of soil on the fine-scale level is referred to as soil ecomorphs (Zhukov, Zadorozhnaya, 2016; Zhukov et al., 2018). These soil patterns influence the herb layer stratum. We found that understory species composition was best explained by the soil mechanical impedance, litter depth, soil temperature and soil moisture, and soil aggregate structure. It is also necessary to note the role of overstorey in the variation of soil properties. Mechanical impedance of the soil is a very important and ecologically relevant soil property, which is considered as a factor influencing the living conditions of plants (Zhukov, Gadorozhnaya, 2016; Zadorozhnaya et al., 2018). The general pattern of tree induced variability of soil properties is due to the difference between the effect of litter and the adjacent opening or neighboring tree (Zinke, 1962). The litter thickness is an important factor influencing the soil temperature (MacKinney, 1929) and can reduce the effects of soil temperature extremes and moderate minimum and maximum temperature values (Fekete et al., 2016). The soil moisture is positively dependent on forest litter thickness (Xing et al., 2018). On the other hand, soil moisture considerably effects leaf litter decomposition. In wetter conditions, a higher level of litter decomposition occurs in general (Yoon et al., 2014). Soil aggregate structure is critical to plant growth (Barthes, Rose, 2002; Canton et al., 2009). But the reverse is also true: vegetation affects soil structure at different scales and through a wide variety of mechanisms (Angers, Caron, 1998).

\section{Conclusion}

The local variation in the studied herb layer community was best explained by soil mechanical impedance (at the depth 0-5, 30-35, 55-60, 60-65, 65-70, 75-80, 80-85, 85-90, and 90-95 cm), soil electrical conductivity, litter thickness, soil temperature, wetness, density, and aggregate structure (isometric log ratios variables $2,3,4,6,7)$. A considerable part of the pant community variation explained by soil factors was spatially structured. The orthogonal eigenvector-based spatial variables (dbMEMs) approach can be extended to quantifying the effect of forest structures on the herb layer community. The measurement of the overstorey spatial structure, which is based on the evaluation of its density, was very useful to explain the variation of the herb layer community.

\section{Acknowledgements}

The authors are grateful to the staff of the "Dniprovsko-Orilsky" Nature Reserve for their support and assistance with this research. We thank Paul Bradbeer for checking the English text and the two anonymous reviewers for helping us to improve earlier versions of this paper. 


\section{References}

Aiba, M., Takafumi, H. \& Hiura T. (2012). Interspecific differences in determinants of plant species distribution and the relationships with functional traits. J. Ecol., 100. 950-957. DOI: 10.1111/j.1365-2745.2012.01959.x.

Aitchison, J. (1986). The statistical analysis of compositional data. London: Chapman and Hall.

Aitchison, J. \& Greenacre M. (2002). Biplots of Compositional Data. Journal of the Royal Statistical Society: Series C (Applied Statistics), 51, 375-392. DOI: 10.1111/1467-9876.00275.

Andivia, E., Fernández, M., Alejano, R. \& Vázquez-Piqué J. (2015). Tree patch distribution drives spatial heterogeneity of soil traits in cork oak woodlands. Ann. For. Sci., 72, 549-559. DOI: 10.1007/s13595-015-0475-8.

Angers, D.A. \& Caron J. (1998). Plant-induced Changes in Soil Structure: Processes and Feedbacks. Biogeochemistry, 42(1-2), 55-72. DOI: 10.1023/A:1005944025343.

Baddeley, A. \& Turner R. (2005). Spatstat: an R package for analyzing spatial point patterns. Journal of Statistical Software, 12, 1-42. DOI: 10.18637/jss.v012.i06.

Barthes, B. \& Roose E. (2002). Aggregate stability as an indicator of soil susceptibility to runoff and erosion; validation at several levels. Catena, 47(2), 133-149. DOI: 10.1016/S0341-8162(01)00180-1.

Binkley, D. \& Giardina C. (1998). Why do tree species affect soils? The warp and woof of tree-soil interactions. Biogeochemistry, 42(1-2), 89-106. DOI: 10.1023/A:1005948126251.

Blanchet, F.G., Legendre, P. \& Borcard D. (2008). Forward selection of explanatory variables. Ecology, 89(9), 26232632. DOI: $10.1890 / 07-0986.1$.

Blank, L. \& Carmel Y. (2012). Woody vegetation patch type determines herbaceous species richness and composition in Mediterranean ecosystem. Community Ecol., 13, 72-81. DOI: 10.1556/ComEc.13.2012.1.9.

Boogaart van der, K.G., Tolosana-Delgado, R. \& Bren M. (2018). Compositions: Compositional Data Analysis. R package version 1.40-2. https://CRAN.Rproject.org/package=compositions

Borcard, D. \& Legendre P. (2002). All-scale spatial analysis of ecological data by means of principal coordinates of neighbour matrices. Ecol. Model., 153, 51-68. DOI: 10.1016/S0304-3800(01)00501-4.

Bratton, S. (1976). Resource division in an understory herb community: responses to temporal and microtopographic gradients. Am. Nat., 110(974), 679-693. www.jstor.org/stable/2459584.

Breshears, D., Rich, P., Barnes, F. \& Campbell K. (1997). Overstorey-imposed heterogeneity in solar radiation and soil moisture in a semiarid woodland. Ecol. Appl., 7(4), 1201-1215. DOI: 10.2307/2641208.

Buzuk, G.N. (2017). Phytoindication with ecological scales and regression analysis: environmental index. Bulletin of Pharmacy, 2 (76), 31-37.

Canton, Y., Sole-Benet, A., Asensio, C., Chamizo, S. \& Puigdefabregas J. (2009). Aggregate stability in range sandy loam soils Relationships with runoff and erosion. Catena, 77, 192-199. DOI: 10.1016/j.catena.2008.12.011.

Chang, L.-W., Zelený, D., Li, C.-F., Chiu, S.-T. \& Hsieh C.-F. (2013). Better environmental data may reverse conclusions about niche-and dispersal-based processes in community assembly. Ecology, 94, 2145-2151. DOI: 10.1890/12-2053.1.

Chase, J.M. (2014). Spatial scale resolves the niche versus neutral theory debate. J. Veg. Sci., 25, 319-322. DOI: $10.1111 /$ jvs.12159.

Chudomelová, M., Zelený, D. \& Li Ch.-F. (2017). Contrasting patterns of fine-scale herb layer species composition in temperate forests. Acta Oecol., 80, 24-31. DOI: 10.1016/j.actao.2017.02.003.

Cottenie, K. (2005). Integrating environmental and spatial processes in ecological community dynamics. Ecol. Lett., 8, 1175-1182. DOI: 10.1111/j.1461-0248.2005.00820.x.

Dallas, T. \& Drake J.M. (2014). Relative importance of environmental, geographic, and spatial variables on zooplankton metacommunities. Ecosphere, 5(9), 104. DOI: 10.1890/ES14-00071.1.

De la Cruz, M. (2008). Metodos para analizar datos puntuales. In F.T. Maestre, A. Escudero \& A. Bonet (Eds.), Introduccion al Analisis Espacial de Datos en Ecologia y Ciencias Ambientales: Metodos y Aplicaciones (pp. 76-127). Madrid: Asociacion Espanola de Ecologia Terrestre, Universidad Rey Juan Carlos y Caja de Ahorros del Mediterraneo.

Didukh, Ya.P. (2011). The ecological scales for the species of Ukrainian flora and their use in synphytoindication. Kyiv: Phytosociocentre.

Dixon, P.M. (2002). Nearest-neighbor contingency table analysis of spatial segregation for several species. Ecoscience, 9(2), 142-151. https://www.jstor.org/stable/42901478

Dray, S., Bauman, D., Blanchet, G., Borcard, D., Clappe, S., Guenard, G., Jombart, T., Larocque, G., Legendre, P., Madi, N. \& Wagner H.H. (2018). adespatial: Multivariate multiscale spatial analysis. R package version 0.3-2. https://CRAN.R-project.org/package=adespatial. 
Egozcue, J.J., Pawlowsky-Glahn, V., Mateu-Figueras, G. \& Barcel'o-Vidal C. (2003). Isometric logratio transformations for compositional data analysis. Mathematical Geology, 35(3), 279-300. DOI: 10.1023/A:1023818214614.

Elliott, K.J., Vose, J.M., Knoepp, L.D., Clinton, B.D. \& Kloeppel B.D. (2015). Functional role of the herbaceous layer in eastern deciduous forest ecosystems. Ecosystems, 18(2), 221-236. DOI: 10.1007/s10021-014-9825-x.

Fekete, I., Varga, C., Biró, B., Tóth, J.A., Várbíró, G., Lajtha, K., Szabó, S. \& Kotroczó Z. (2016). The effects of litter production and litter depth on soil microclimate in a Central European deciduous forest. Plant Soil, 398 (1-2), 291-300. DOI: 10.1007/s11104-015-2664-5.

Fortin, M.-J. \& Dale M. (2005). Spatial analysis: Guide for ecologists. Cambridge: Cambridge University Press.

Frelich, L.E., Machado, J.L. \& Reich P.B. (2003). Fine scale environmental variation and structure of understorey plant communities in two old growth pine forests. J. Ecol., 91, 283-293. DOI: 10.1046/j.1365-2745.2003.00765.x.

Gazol, A. \& Ibanez R. (2010). Plant species composition in a temperate forest: Multi-scale patterns and determinants. Acta Oecol., 36, 634-644. DOI: 10.1016/j.actao.2010.09.009.

Gilbert, B. \& Lechowicz M.J. (2004). Neutrality, niches, and dispersal in a temperate forest understory. Proc. Nat. Acad. Sci. USA, 101(20), 7651-7656. DOI: 10.1073/pnas.0400814101.

Gilliam, F.S., Turrill, N.L. \& Adams M.B. (1995). Herbaceous-layer and overstorey species in clear-cut and mature central Appalachian hardwood forests. Ecol. Appl., 5, 947-955. DOI: 10.2307/2269345.

Gilliam, F.S. (2007). The ecological significance of the herbaceous layer in temperate forest ecosystems. Bioscience, 57, 845-858. DOI: 10.1641/B571007.

Griffith, D.A. (1992). What is spatial autocorrelation? Reflections on the past 25 years of spatial statistics. L'Espace Géographique, 21, 265-280.

Hurlbert, S.H. (1984). Pseudoreplication and the design of ecological field experiments. Ecol. Monogr., 54(2), 187211. DOI: $10.2307 / 1942661$.

Jones, C.G., Lawton, J.H. \& Shachak M. (1994). Organisms as ecosystem engineers. Oikos, 69, 373-386. DOI: $10.2307 / 3545850$.

Jones, M.M., Tuomisto, H., Clark, D.B. \& Olivas P. (2006). Effects of mesoscale environmental heterogeneity and dispersal limitation on floristic variation in rainforest ferns. J. Ecol., 94, 181-195. DOI: 10.1111/j.13652745.2005.01071.x.

Jones, M.M., Tuomisto, H., Borcard, D., Legendre, P., Clark, D.B. \& Olivas P.C. (2008). Explaining variation in tropical plant community composition: influence of environmental and spatial data quality. Oecologia, 155, 593-604. DOI: $10.1007 /$ s00442-007-0923-8.

Karst, J., Gilbert, B. \& Lechowicz M.J. (2005). Fern community assembly: the roles of chance and the environment at local and intermediate scales. Ecology, 86, 2473-2486. DOI: 10.1890/04-1420.

King, A.W. \& With K.A. (2002). Dispersal success on spatially structured landscapes: when do spatial pattern and dispersal behavior really matter? Ecol. Model., 147(1), 23-39. DOI: 10.1016/S0304-3800(01)00400-8.

Laliberte, A.S., Rango, A., Herrick, J.E., Fredrickson, E.L. \& Burkett L. (2009). An object-based image analysis approach for determining fractional cover of senescent and green vegetation with digital plot photography. J. Arid Environ., 69, 1-14. DOI: 10.1016/j.jaridenv.2006.08.016.

Legendre, P. \& Fortin M.J. (1989). Spatial pattern and ecological analysis. Vegetatio, 80(2), 107-138. DOI: 10.1007/ BF00048036.

Legendre, P. (1993). Spatial autocorrelation: trouble or new paradigm? Ecology, 74, 1659-1673. DOI: 10.2307/1939924.

Legendre, P. \& Gallagher E.D. (2001). Ecologically meaningful transformations for ordination of species. Oecologia, 129(2), 271-280. DOI: 10.1007/s004420100716.

Legendre, P., Mi, X., Ren, H., Ma, K., Yu, M., Sun, I.-F. \& He F. (2009). Partitioning beta diversity in a subtropical broadleaved forest of China. Ecology, 90, 663-674. DOI: 10.1890/07-1880.1.

Legendre, P. \& Legendre L. (2012.) Numerical ecology. Amsterdam: Elsevier Science.

Legendre, P. \& Gauthier O. (2014). Statistical methods for temporal and space-time analysis of community composition data. Proc. R. Soc. B, 281(1778), 20132728. DOI: 10.1098/rspb.2013.2728.

Lennon, J.J. (2000). Red-shifts and red herrings in geographical ecology. Ecography, 23, 101-113. DOI: 10.1111/ j.1600-0587.2000.tb00265.x.

Levin, D.A. \& Wilson A.C. (1976). Rates of evolution in seed plants: Net increase in diversity of chromosome numbers and species numbers through time. Proc. Nat. Acad. Sci., 73(6), 2086-2090. DOI: 10.1073/pnas.73.6.2086.

Lososová, Z., Šmarda, P., Chytrý, M., Purschke, O., Pyšek, P., Sádlo, J., Tichý, L. \& Winter M. (2015). Phylogenetic structure of plant species pools reflects habitat age on the geological time scale. J. Veg. Sci., 26, 1080-1089. DOI: $10.1111 /$ jvs.12308. 
Lyon, J. \& Sharpe W.E. (2003). Impacts of hay-scented fern on nutrition of northern red oak seedlings. J. Plant Nutr., 26(3), 487-502. DOI: 10.1081/PLN-120017661.

MacKinney, A.L. (1929). Effects of forest litter on soil temperature and soil freezing in autumn and winter. Ecology, 10(3), 312-321. DOI: 10.2307/1929507.

Mölder, A., Bernhardt-Römermann, M. \& Schmidt W. (2008). Herb-layer diversity in deciduous forests: raised by tree richness or beaten by beech? For. Ecol. Manag., 256(3), 272-281. DOI: 10.1016/j.foreco.2008.04.012.

Nettesheim, F.C., Garbin, M.L., Rajão, P.H.M., Araujo, D.S.D. \& Grelle C.E.V. (2018). Environment is more relevant than spatial structure as a driver of regional variation in tropical tree community richness and composition. Plant Ecology \& Diversity, DOI: 10.1080/17550874.2018.1473520.

Oijen, D., Feijen, M., Hommel, P., Ouden, J. \& Waal R. (2005). Effects of tree species composition on within-forest distribution of understorey species. Appl. Veg. Sci., 8(2), 155-166. DOI: 10.1111/j.1654-109X.2005.tb00641.x.

Oksanen, J., Blanchet, F.G., Kindt, R., Legendre, P., Minchin, P.R., O’Hara, R.B., Simpson, G.L., Solymos, P., Stevens, M.H.H. \& Wagner H. (2018). Community ecology package. R package version 2.5-2. https:/CRAN.R-project. org/package= vegan

Paluch, J.G. \& Gruba P. (2012). Effect of local species composition on topsoil properties in mixed stands with silver fir (Abies alba Mill.). Forestry: An International Journal of Forest Research, 85(3), 413-426. DOI: 10.1093/ forestry/cps040.

Parent, L., de Almeida, C., Hernandes, A., Egozcue, J.J., Gülser, C., Bolinder, M.A., Kätterer, T., Andrén, O., Parent, S.E., Anctil, F., Centurion, J.F. \& Natale W. (2012). Compositional analysis for an unbiased measure of soil aggregation. Geoderma, 179-180, 123-131. DOI: 10.1016/j.geoderma.2012.02.022.

Pennisi, B.V. \& van Iersel M. (2002). Three ways to measure medium EC. GMPro, 22(1), 46-48.

Rao, C.R. (1964). The use and interpretation of principal component analysis in applied research. Sankhyā: The Indian Journal of Statistics, Series A, 26, 329-358. https://www.jstor.org/stable/25049339

Siefert, A., Ravenscroft, C., Althoff, D., Alvarez-Y Epiz, J.C., Carter, B.E., Glennon, K.L., Heberling, J.M., Jo, I.S., Pontes, A., Sauer, A., Willis, A. \& Fridley J.D. (2012). Scale dependence of vegetation-environment relationships: a meta-analysis of multivariate data. J. Veg. Sci., 23, 942-951. DOI: 10.1111/j.1654-1103.2012.01401.x.

Silvertown, J., McConway, K., Gowing, D., Dodd, M., Fay, M.F., Joseph, J.A. \& Dolphin K. (2006). Absence of phylogenetic signal in the niche structure of meadow plant communities. Proc. R. Soc. B, 273, 39-44. DOI: 10.1098/ rspb.2005.3288.

Smith, T.W. \& Lundholm J.T. (2010). Variation partitioning as a tool to distinguish between niche and neutral processes. Ecography, 33, 648-655. DOI: 10.1111/j.1600-0587.2009.06105.x.

Standovár, T., Ódor, P., Aszalós, R. \& Gálhidy L. (2006). Sensitivity of ground layer vegetation diversity descriptors in indicating forest naturalness. Community Ecol., 7(2), 199-209. DOI: 10.1556/ComEc.7.2006.2.7.

Stohlgren, T.J., Owen, A.J. \& Lee M. (2000). Monitoring shifts in plant diversity in response to climate change: a method for landscapes. Biodivers. Conserv., 9(1), 65-86. DOI: 10.1023/A:1008995726486.

Teng, S.N., Xu, C., Sandel, B. \& Svenning J-C. (2018). Effects of intrinsic sources of spatial autocorrelation on spatial regression modelling. Methods in Ecology and Evolution, 9, 363-372. DOI: 10.1111/2041210X.12866.

Tobler, W. (1970). A computer movie simulating urban growth in the Detroit region. Economic Geography, 46(1), 234-240. DOI: $10.2307 / 143141$

Vadunina, A.F. \& Korchagin S.A. (1986). Methods for research of physical properties of the soil. Moscow: Agropromizdat.

von Oheimb, G. \& Härdtle W. (2009). Selection harvest in temperate deciduous forest: impact on herb layer richness and composition. Biodivers. Conserv., 18(2), 271-287. DOI: 10.1007/s10531-008-9475-4.

Weiher, E., Freund, D., Bunton, T., Stefanski, A., Lee, T. \& Bentivenga S. (2011). Advances, challenges and a developing synthesis of ecological community assembly theory. Philos. Trans. R. Soc. Lond. B, 366, 2403-2413. DOI: 10.1098/rstb.2011.0056.

Westhoff, V. \& van der Maarel E. (1978). The Braun-Blanquet approach. In R.H. Whittaker (Ed.), Classification of plant communities (pp. 289-399). Hague: W. Junk.

Whigham, D.F. (2004). The ecology of woodland herbs in temperate deciduous forests. Annual Review of Ecology, Evolution, and Systematics, 35, 583-621. DOI: 10.1146/annurev.ecolsys.35.021103.105708.

Xing, Z., Yan, D., Wang, D., Liu, Sh. \& Dong G. (2018). Experimental analysis of the effect of forest litter cover on surface soil water dynamics under continuous rainless condition in North China. Kuwait Journal of Science, 45(2), 75-83. 
Yoon, T. K., Noh, N. J., Han, S., Lee, J. \& Son Y. (2014). Soil moisture effects on leaf litter decomposition and soil carbon dioxide efflux in wetland and upland forests. Soil Sci. Soc. Am. J., 78, 1804-1816. DOI: 10.2136/sssaj2014.03.0094.

Zadorozhnaya, G.A., Andrusevych, K.V. \& Zhukov O.V. (2018). Soil heterogeneity after recultivation: ecological aspect. Folia Oecol., 45(1), 46-52. DOI: 10.2478/foecol-2018-0005.

Zhukov, A. \& Gadorozhnaya G. (2016). Spatial heterogeneity of mechanical impedance of a typical chernozem: the ecological approach. Ekológia (Bratislava), 35, 263-278. DOI: 10.1515/eko-2016-0021.

Zhukov, A.V. \& Zadorozhnaya G.A. (2016). Ecomorphes of the sod-lithogenic soils on reddish-brown clays. Issues of Steppe Forestry and Forest Reclamation of Soils, 45, 91-103.

Zhukov, O., Kunah, O., Dubinina, Y. \& Novikova V. (2018). The role of edaphic and vegetation factors in structuring beta diversity of the soil macrofauna community of the Dnipro river arena terrace. Ekológia (Bratislava), 37(3), 301-327. DOI: 10.2478/eko-2018-0023.

Zinke, P. (1962). The pattern of influence of individual forest trees on soil properties. Ecology, 43(1), 130-133. DOI: 10.2307/1932049. 